\title{
Ampla abordagem sobre a dermatite atópica: revisão narrativa
}

\author{
Broad approach to atopic dermatitis: narrative review
}

Abordaje amplio de la dermatitis atópica: revisión narrative

Laís Assunção Vilefort ${ }^{1 *}$, Isabella Vilaça de Oliveira Melo ${ }^{1}$, Bruna do Nascimento Cardoso ${ }^{1}$, Ana Carolina Mohr², Denise Ferreira Bomfim Motta ${ }^{2}$, Fernanda Paula Atavila ${ }^{3}$, lago Pordeus Casimiro ${ }^{4}$, Denis da Silva Guedes ${ }^{5}$, Gabrielle Fernanda Cerbarro ${ }^{5}$, Pedro Henrique Zuba Xavier ${ }^{6}$.

\section{RESUMO}

Objetivo: Fornecer através de uma revisão narrativa uma ampla abordagem sobre a Dermatite Atópica (DA). Revisão bibliográfica: A dermatite atópica ou eczema atópico, como também é chamada, se refere a uma inflamação crônica da pele, caracterizada porlesões avermelhadas, pruriginosas e com processos descativos associados. Trata-se de uma doença recidivante, que acomete principalmente a faixa etária pediátrica, mas pode acometer também indivíduos na fase adulta. A fisiopatologia conhecida até o momento relaciona o desenvolvimento da doença à uma interação entre fatores genéticos, alterações da barreira cutânea e distúrbios imunológicos. O diagnóstico dessa patologia é essencialmente clínico e a realização de exames complementares auxiliam na determinação de alguns fatores desencadeantes das lesões. O tratamento é feito basicamente com a retirada de fatores desencadeantes e, quando necessário, com corticosteroides e outros medicamentos. Considerações finais: A dermatite atópica é uma doença crônica que af eta milhares de pessoas em todo mundo. Na presença de sinais e sintomas sugestivos, o indivíduo deve procurar o médico, preferencialmente dermatologista, para estabelecimento de um diagnóstico preciso e instituição de um plano terapêutico adequado.

Palavras-chave: Dermatite atópica, Eczema atópico, Dermatite.

\begin{abstract}
Objective: To provide, through a narrative review, a broad approach to Atopic Dermatitis (AD). Bibliography review: Atopic dermatitis or atopic eczema, as it is also called, refers to a chronic inflammation of the skin, characterized by red, itchy lesions and associated descative processes. It is a recurrent disease, which mainly affects the pediatric age group, but it can also affect individuals in adulthood. The pathophysiology known so far relates the development of the disease to an interaction between genetic factors, changes in the skin barrier and immunological disorders. The diagnosis of this pathology is essentially clinical and the performance of complementary exams help to determine some triggering factors for the lesions. Treatment is basically done with the removal of triggering factors and, when necessary, with corticosteroids and other medications. Final considerations: Atopic dermatitis is a chronic disease that affects thousands of people worldwide. In the presence of suggestive signs and symptoms, the individual should seek a physician, preferably a dermatologist, to establish an accurate diagnosis and institute an adequate therapeutic plan.
\end{abstract}

Key words: Dermatitis atopic, Eczema, Dermatitis.

\section{RESUMEN}

Objetivo: Proporcionar, a través de una revisión narrativa, un enfoque amplio de la Dermatitis Atópica (DA). Revisión bibliográfica: La dermatitis atópica o eccema atópico, como también se le llama, se refiere a una inflamación crónica de la piel, caracterizada por lesiones rojas, pruriginosas y procesos de descamación

\footnotetext{
${ }^{1}$ Faculdade de Minas de Belo Horizonte (FAMINAS-BH), Belo Horizonte - MG. *E-mail: lavilefort@gmail.com

2 Pontifícia Universidade Católica de Minas Gerais (PUC-MINAS), Betim - MG.

${ }^{3}$ Instituto Tocantinense Presidente Antônio Carlos (IAPAC-PALMAS), Palmas - TO.

${ }^{4}$ Centro Universitário Facisa (UNIFACISA), Campina Grande - PB.

${ }^{5}$ Faculdade São Leopoldo Mandic (SLMANDIC), Araras - SP.

6 Universidade Estadual do Sudoeste da Bahia (UESB), Vitória da Conquista - BA.
} 
asociados. Es una enfermedad recurrente, que afecta principalmente al grupo de edad pediátrica, pero también puede afectar a individuos en la edad adulta. La fisiopatología conocida hasta ahora relaciona el desarrollo de la enfermedad con una interacción entre factores genéticos, cambios en la barrera cutánea y trastornos inmunológicos. El diagnóstico de esta patología es fundamentalmente clínico y la realización de exámenes complementarios ayuda a determinar algunos factores desencadenantes de las lesiones. El tratamiento se realiza básicamente con la eliminación de los factores desencadenantes y, cuando sea necesario, con corticosteroides y otros medicamentos. Consideraciones finales: La dermatitis atópica es una enfermedad crónica que af ecta a miles de personas en todo el mundo. En presencia de signos y síntomas sugestivos, el individuo debe buscar un médico, preferiblemente un dermatólogo, para establecer un diagnóstico preciso e instituir un plan terapéutico adecuado.

Palabras clave: Dermatitis atópica, Eccema atópico, Dermatitis.

\section{INTRODUÇÃO}

De caráter recidivante e crônico, a Dermatite Atópica (DA) é considerada uma doença inflamatória da pele, caracterizada porprurido intenso e lesões do tipo eczematosas, que, muitas vezes, possuem início na primeira infância em aproximadamente $85 \%$ dos casos. Sua associação com outras manifestações atópicas, como a asma e a rinite alérgica é frequente. Como não existem exames laboratoriais específicos para o diagnóstico da DA assim como não existe uma definição padronizada para ela, assim como a realização de estudos epidemiológicos, a uniformização do diagnóstico é dificultada. Sendo assim, esta patologia acarreta transtornos em toda a estrutura familiar do paciente, compromete as atividades de trabalho e lazer e o desempenho escolar (CASTRO APM, et al., 2006).

Sendo assim, torna-se extremamente importante que seja feito um diagnóstico de maneira cuidadosa, com base em critérios bem estabelecidos, de modo em que os pacientes possam ser classificados em grupos semelhantes, com classificação realizada sempre com os mesmos critérios. É muito provável que dentro da denominação de DA, assim como ocorre entre outras manifestações alérgicas, várias outras doenças, com características clínicas semelhantes, sejam enquadradas. Além disso, há uma forte correlação de DA com outras condições atópicas como a rinite alérgica e a asma (KOLB L e BRUKER SJF, 2022).

Desta forma, deve ser idealmente conceituada como uma síndrome que engloba várias apresentações fenotípicas. Diante disso, o termo síndrome de dermatite e eczema atópicos (AEDS) foi proposto pela Academia Europeia de Alergia e Imunologia Clínica, mas não é unânime entre todos os grupos que trabalham com DA a sua aceitação (KOLB L e BRUKER SJF, 2022).

Cerca de $50 \%$ dos pacientes com dermatite atópica apresentam as primeiras manifestações clínicas durante o primeiro ano de vida. Em contrapartida, aproximadamente $40 \%$ dessas crianças com DA no início da vida desenvolvem, aos cinco anos, doenças alérgicas respiratórias. Assim como outras doenças atópicas, a expressão sintomática de DA envolve a interação de múltiplos genes, do sistema imunológico e do ambiente. Entretanto, a hipótese da participação de alérgeno na etiopatogênese da DA não é unânime devido ao reconhecimento de vários agentes provocadores de exacerbações, de origem não alérgica. Em consequência, o manejo dos pacientes torna-se complexo (TORRES T, et al., 2019).

O objetivo desta revisão foi fornecer uma ampla abordagem acerca da dermatite atópica, uma doença da pele extremamente comum que af eta milhões de pessoas em todo o mundo.

\section{REVISÃO BIBLIOGRÁFICA}

\section{Fatores de risco para dermatite atópica}

Dentre os principais fatores de risco para o desenvolvimento da DA destacam-se os fatores hereditários, imunológicos e ambientais. Um fator de risco considerável para o desenvolvimento desta patologia envolve a presença de irmãos ou pais com atopia, sendo cerca de $70 \%$ de chance de um filho desenvolver DA em casos em que ambos os pais apresentem a doença. Apesar de existirem alguns estudos que demonstram discreto 
predomínio entre pacientes do sexo feminino, não há evidências de que há distribuição preferencial quanto ao sexo FURUE M, et al., 2019).

Vários estudos têm tentado identificar marcadores imunológicos para o desenvolvimento de doenças alérgicas, entre elas a DA. Avaliou-se a presença de $\operatorname{lgE}$ em sangue de cordão, a menor produção de interferon gama em lactentes e crianças maiores de um ano de idade e a produção de Interleucinas (IL), entretanto, a baixa sensibilidade e especificidade destes achados não permitem sua utilização na prática clínica. É importante ressaltar que a associação de DA com outras doenças alérgicas é bastante comum (CABANILLAS B, et al., 2017).

Os fatores ambientais têm sido muito estudados. Existem estudos epidemiológicos que apontam uma maior prevalência de DA em famílias menores e com nível socioeconômico mais elevado, principalmente em casos em que a mãe possui maior grau de escolaridade e vive em ambientes urbanos. A principal hipótese que justificativa esses achados é a higiene, que atribui ao estilo de vida nas cidades ocidentais uma maior frequência de alergia, já que normalmente há menor contato com determinados vírus e bactérias, que estimulam setores específicos do sistema imunológico contribuindo para menor intensidade da resposta alérgica, entretanto, não há estudos que confirmem esta hipótese no Brasil até o momento (WILLIAMS HC e CHALMERS J, 2020).

\section{Epidemiologia da dermatite atópica}

A incidência da dermatite atópica aumentou cerca de 2 a 3 vezes nas nações industrializadas desde a década de 1970 , com aproximadamente $15 \%$ a $20 \%$ das crianças e $1 \%$ a $3 \%$ dos adultos af etados em todo o mundo. Estudos de base populacional nos Estados Unidos sugerem que a prevalência gira em torno de $10,7 \%$ para crianças e $7,2 \%$ para adultos ( $\mathrm{KATOH} N$, et al., 2020).

$\mathrm{O}$ início da doença pode ocorrer em qualquer idade, mas comumente se manifesta nos primeiros 5 anos de vida, com a maior incidência entre 3 e 6 meses. Aproximadamente $60 \%$ dos pacientes desenvolvem a doença no primeiro ano de vida e $90 \%$ nos primeiros 5 anos de vida. Cerca de $20 \%$ das crianças que desenvolvem DA antes dos 2 anos de idade terão sintomas persistentes da doença, $17 \%$ terão sintomas intermitentes aos 7 anos de idade e apenas 16,8\% dos adultos com DA experimentam o início após a adolescência. A doença geralmente se resolve no momento em que a criança atinge a idade adulta, entretanto, aproximadamente $10 \%$ a $30 \%$ dos pacientes continuarão a apresentar sintomas (TORRES T, et al., 2019).

\section{Fatores desencadeantes da dermatite atópica}

Dentre os principais fatores desencadeantes das crises da dermatite atópica estão: agentes infecciosos, aeroalérgenos, autoantígenos e fatores neuro-psico-imunológicos. Vários estudos têm demonstrado a relevância dos aeroalérgenos em provocar ou agravar as lesões eczematosas da DA. Entre eles destacam se os ácaros da poeira domiciliar, os animais domésticos, as baratas e os fungos50. Os alérgenos de ácaros são os mais envolvidos na sensibilização atópica (YOSIPOVITCH G, et al., 2020).

Os pacientes com esse tipo de dermatite possuem a pele mais suscetível a colonizações por microrganismos e, consequentemente, infecções, sendo a deficiência de peptídeos antimicrobianos um fator facilitador dessas infecções. Esses peptídeos compõem um componente do sistema imunológico inato, sendo sintetizados na epiderme. Eles são necessários para o funcionamento rápido e efetivo na defesa do hospedeiro contra vírus, bactérias e fungos (CASTRO APM, et al., 2006).

Recentemente, auto-antígenos $\lg E$ reativos contra proteínas humanas foram clonados e representam primariamente proteínas intracelulares. Estes auto-antígenos são o Hom s 1-5 e DSF70 que tem sido detectados no soro sob a forma de complexos imunes de lgE e parecem atuar como adjuvantes no mecanismo imunológico. Desta forma, a resposta imunológica que é primariamente iniciada por alérgenos ambientais, pode ser mantida por antígenos endógenos, particularmente na DA grave (WOODS CA, 2017).

Um fatorque pode exacerbar a DA é o estresse emocional. Embora o mecanismo exato da interação entre o sistema imunológico cutâneo e o sistema nervoso não tenha ainda sido identificado, acredita-se que este 
fenômeno deva ser mediado por fatores neuroimunológicos como os neuropeptídeos. Na DA, esses neuropeptídeos podem desregular a produção de citocinas e outros fatores que resultam na redução da defesa do hospedeiro. Níveis plasmáticos elevados de NGF (fator de crescimento do nervo) e Substância $P$ (SP) podem ser encontrados em pacientes com DA e se relacionam positivamente com a atividade da doença (YOSIPOVITCH G, et al., 2020).

\section{Fisiopatologia da dermatite atópica}

A fisiopatologia da DA não está totalmente esclarecida e tem sido demonstrada inter-relação complexa envolvendo fatores genéticos, imunitários, ambientais, psicossomáticos, farmacológicos e alteração da própria estrutura da pele. Recentemente, a DA foi classificada segundo o ponto de vista fisiopatológico em extrínseca e intrínseca. A extrínseca, também chamada de alérgica, atinge cerca de $70 \%$ a $80 \%$ dos pacientes com $\mathrm{DA}$ e se relaciona à níveis elevados de lgE e sensibilização contra alérgenos ambientais. Por sua vez, a intrínseca, também chamada de não alérgica, ocorre nos outros $20 \%$ a $30 \%$ dos casos e é caracterizada pela ausência de detecção de sensibilização alergênica e baixos níveis de lgE. Os dois distúrbios principais da DA são a disfunção da barreira cutânea e da resposta imunológica havendo uma inter-relação entre os dois, o que ocasiona um círculo vicioso (ANTUNES AA, et al., 2017).

A barreira cutânea é formada pelo Estrato Córneo (EC), constituído de um compartimento duplo, heterogêneo, onde os principais elementos são os corneócitos e os lipídeos extracelulares. Os lipídeos extracelulares do estrato córneo são compostos fundamentalmente de quantidades equimolares de ceramidas (45\%-50\%), colesterol (25\%) e ácidos graxos livres (10\%-15\%). As ceramidas, caracterizadas por mais de sete subfrações são essenciais para a função de barreira. Uma das principais funções da barreira cutânea é o controle da permeabilidade (FRAZIER W e BHARDWAJ N, 2020).

Quando há perda desta função, a pele passa a sofrer as consequências de agressões físicas, químicas ou biológicas. A xerose ou pele seca na DA está relacionada a alterações da diferenciação epidérmica, do metabolismo lipídico da epiderme e ao aumento da perda de água trans-epidérmica. Os corneócitos tendem a se agregar, são menores, com renovação celular reduzida, e contêm menor quantidade de aminoácidos hidrossolúveis derivados da filagrina, que exerce papel importante na perda de água trans-epidérmica. A composição alterada dos lipídeos do extrato córneo é o defeito básico da DA levando a aumento da permeabilidade a alérgenos e irritantes (FURUE M, et al., 2019).

As ceramidas são as principais moléculas de retenção de água no espaço extracelular do envelope cornificado. Essas ceramidas, em especial as subfrações 1 e 3, estão signific ativamente reduzidas na DA, tanto na pele com ou sem lesão. Esta redução pode ser explicada por alterações das enzimas que agem no metabolismo das ceramidas, especialmente a glucosilceramida-esfingomielina deacilase, a betaglucocerebrosidase, e a esfingomielinase(KATOH N, et al., 2020).

Um outro fator são os glicerofosfolipídeos, produtos bacterianos que funcionam como ceramidases, e hidrolisam as ceramidas24. Na interface entre a pele e o meio ambiente existe número elevado de antígenos. O prurido intenso e a escarificação em combinação com a hiper-reatividade cutânea e a redução do limiar ao prurido, são a base do círculo vicioso na DA. Como consequência do ato de coçar ocorre estimulação mecânica contínua e liberação de citocinas pelos queratinócitos (KOLB L e BRUKER SJF, 2022).

\section{Manifestações clínicas da dermatite atópica}

É difícil def inir as manif estações clínicas da dermatite atópica devido à grande heterogeneidade em termos de suas características, gravidade e curso. É comum a presença de lesões eczematosas, que geralmente apresentam uma distribuição corporal relacionada à idade, as lesões são pruriginosas, crônicas e possuem períodos de remissão e atividade (MINEOKA RT e KATOH N, 2020).

Bebês frequentemente apresentam lesões agudas, caracterizadas por eritema mal definido com edema, vesículas, escoriações e exsudato seroso, os quais podem ser amplamente distribuídos, mas normalmente costumam envolver bochechas e tronco. A partir dos 2 anos de idade, o eczema torna-se mais localizado e 
crônico, com eritema, pele seca (xerose) e lesões mal definidas comumente afetando superfícies flexoras com espessamento (liquenificação) dessas áreas crônicas (CASTRO APM, et al., 2006).

Apesar de adolescentes e adultos geralmente apresentarem eczema difuso, eles também podem ter lesões localizadas que normalmente af etam as mãos, pálpebras e áreas flexoras. Adultos também podem ter eczema apenas de mãos ou dermatite de cabeça e pescoço, envolvendo apenas a parte superior do tronco, ombros e couro cabeludo (YANG G, et al., 2020).

As variantes morfológicas da dermatite atópica incluem o tipo folicular, caracterizado por pápulas foliculares compactadas, frequentemente observadas em pessoas de ascendência asiática e af ricana e o tipo prurigo, com pápulas escoriadas, endurecidas e nódulos, em pacientes com doença de longa data (ANTUNES AA, et al., 2017).

Outras características comuns vistas na maioria dos pacientes com essa doença são: secura generalizada da pele, doença de início precoce (normalmente nos primeiros 2 anos de vida) ou história familiar de doença atópica (por exemplo, asma, rinite alérgica, dermatite atópica) (MINEOKA RT e KATOH N, 2020).

\section{Diagnóstico e diagnóstico diferencial da dermatite atópica}

A dermatite atópica é um diagnóstico clínico que não possui exame específico, sendo assim, a avaliação de um médico é considerada o padrão ouro. Aproximadamente $80 \%$ dos pacientes são diagnosticados e tratados no ambiente de atenção primária. A Academia Americana de Dermatologia (AAD) simplificou o diagnóstico usando critérios previamente validados (MINEOKA RT e KATOH N, 2020).

Os critérios do AAD se diferenciam em: 1) Características essenciais: história crônica ou recorrente eczema (agudo, subagudo ou crônico), prurido e lesões com morfologia típica e padrões específicos da idade; 2) Características importantes: atopia (história pessoal ou familiar), idade precoce de início, reatividade a imunoglobulina E e xerose; 3) Características associadas: respostas vasculares atípicas (palidez facial, dermografismo branco), ceratose pilar, pitiríase alba, palmas hiperlineares ou ictiose, alterações oculares ou periorbitais, lesões de acentuação perifolicular, liquenificação ou prurigo (ANTUNES AA, et al., 2017).

Como a apresentação da dermatite atópica é diversa, o seu diagnóstico diferencial é bastante extenso. Entre as possíveis doenças estão: dermatite de contato, linfoma cutâneo de células T, dermatite herpetiforme, impetigo, líquen simples crônico, molusco contagioso, eczema numular, psoríase, sarna, dermatite seborréica, urticária, exantemas virais dentre outros (KIM J, et al., 2019).

\section{Tratamento da dermatite atópica}

O manejo da dermatite atópica visa melhorar os sintomas e estabelecer o controle da doença em longo prazo. Os planos de manejo devem ser centrados no paciente e precisam incluir medidas como evitar fatores desencadeantes, restaurar barreiras cutâneas com uso de hidratantes e abordagens que visam reduzir a inflamação de acordo com a gravidade da doença (FISHBEIN AB, et al., 2020).

Uma medida básica que compõe o tratamento dessa afecção é a hidratação da região afetada. Sendo assim, é fundamental compreender que o paciente atópico possui def eito na barreira cutânea, o que torna a pele mais sensível a diversos estímulos. Sendo assim, a hidratação tem o papel de estabilizar a função da barreira epidérmica e realizar umectação do estrato córneo. Para a xerose nesses pacientes, os principais fatores agravantes são: uso excessivo de sabonetes, banhos prolongados e quentes, nadar em piscina com cloro, ar-condicionado, produtos químicos, emolientes inadequados, baixa umidade do ar, poluição aérea, algumas medicações, fricção, estresse e nutrição (FISHBEIN AB, et al., 2020).

Desta forma, para esses pacientes são recomendados banhos mornos e rápidos, evitando o uso de sabões com corantes e fragrâncias. Para a restauração da barreira cutânea é fundamental o uso de emolientes isentos de fragrâncias, preservativos e álcool. Sua aplicação deve ser realizada com a pele ainda úmida, logo após o banho (FRAZIER W e BHARDWAJ N, 2020).

O controle do processo inflamatório é um dos pilares no tratamento da DA e medicamentos como corticosteroides e os inibidores da calcineurina, ambos de uso tópico, têm papel importante no manejo da 
doença. O prurido é um dos sintomas clínicos cardinais na DA. Seu manejo adequado, no entanto, ainda não está bem estabelecido e há dificuldades em se avaliar clinicamente os resultados relacionados às terapêuticas antipruriginosas, especialmente os anti-histamínicos (KIM J, et al., 2019).

\section{Complicações associadas à dermatite atópica}

A infecção é a complicação mais comum da dermatite atópica e deve-se principalmente ao rompimento da epiderme e à desregulação imunológica causada por mutações no gene $F L G$. As infecções podem ser causadas por bactérias, vírus ou fungos (WANG V, et al., 2021).

As infecções bacterianas estão associadas à diminuição da produção de peptídeos antimicrobianos na pele e a um microbioma cutâneo incomum que ocorrem na DA, com diminuição da diversidade e aumento da colonização por Staphylococcus aureus. Aproximadamente $80 \%$ a $90 \%$ dos pacientes com DA são portadores de S. aureus, aumentando o risco de superinfecção das suas lesões cutâneas (impetiginização) (CABANILLAS B, et al., 2017).

Pacientes com DA correm um risco maior de eczema herpético $(E H)$, uma infecção viral aguda com risco de morte, causada pelo vírus herpes simplex. Aproximadamente $20 \%$ dos pacientes com DA desenvolvem $\mathrm{EH}$. É mais comum entre pacientes com doença grave ou doença mediada por lgE. Outra complicação que pode ocorrer é pelo molusco contagioso (MC) que é uma inf ecção viral benigna da pele que se apresenta como pápulas cor da pele, rosa ou branco perolado. O vírus pode durar em média 1 a 2 anos e pode deixar cicatrizes pontiagudas (YANG G, et al., 2020).

As infecções fúngicas, por sua vez, também podem invadir a pele desses pacientes, que está comprometida, levando à colonização por levedura ou tinea. Culturas apropriadas podem ser necessárias em pacientes com fatores de risco ou que permanecem sem resposta ao tratamento (WANG V, et al., 2021).

\section{CONSIDERAÇÕES FINAIS}

A dermatite atópica é uma doença crônica inflamatória da pele muito comum, que atinge milhões de pessoas em todo o mundo, sendo mais comum na faixa etária pediátrica. Sua patogênese envolve fatores genéticos, imunológicos e ambientais e dentre os principais fatores de risco para desenvolver essa doença estão def eitos no gene $F L G$ e história familiar de atopia. O diagnóstico é clínico, baseado na observação das lesões cutâneas, que podem variar de acordo com a idade do paciente e gravidade da doença. Possui diversos diagnósticos diferenciais, aos quais os médicos devem estar atentos. As complicações mais comuns são infecções de pele bacterianas, virais ou fúngicas. O tratamento consiste em terapia antiinflamatória que poderá ser tópica e/ou sistêmica de acordo com a manif estação no momento.

\section{REFERÊNCIAS}

1. ANTUNES AA, et al. Guia prático de atualização em dermatite atópica - Parte I: etiopatogenia, clínica e diagnóstico. Posicionamento conjunto da Associação Brasileira de Alergia e Imunologia e da Sociedade Brasileira de Pediatria. Arquivos de Asma, Alergia e Imunologia, 2017; 1(2).

2. CABANILLAS B, et al. Atopic dermatitis phenotypes and the need for personalized medicine. Current Opinion in Allergy and Clinical Immunology, 2017;17(4):309-315.

3. CASTRO APM, et al. Guia Prático para o Manejo da Dermatite Atópica - opinião conjunta de especialistas em alergologia da Associação Brasileira de Alergia e Imunopatologia e da Sociedade Brasileira de Pediatria. Revista brasileira de alergia e imunopatologia, 2006;29(6): 268-282.

4. FISHBEIN AB, et al. Update on Atopic Dermatitis: Diagnosis, Severity Assessment, and Treatment Selection. The Journal of Allergy and Clinical Immunology: In Practice, 2020;8(1): 91-101.

5. FRAZIER W, BHARDWAJ N. Atopic Dermatitis: Diagnosis and Treatment. American Family Physician, 2020; 101(10):590-598.

6. FURUE M, et al. Pathogenesis of Atopic Dermatitis: Current Paradigm. The Iranian Journal of Immunolog, 2019; 16(2): 97-107.

7. KATOH N, et al. Japanese guidelines for atopic dermatitis 2020. Allergology International, 2020;69(3):356-369.

8. KIM J, et al. Pathophysiology of atopic dermatitis: Clinical implications. Allergy and Asthma Proceedings, 2019; 40(2): 84-92. 
9. KOLB L, BRUKER SJF. Atopic Dermatitis. StatPearls Publishing, 2022.

10. MINEOKA RT, KATOH N. Atopic Dermatitis: Identification and Management of Complicating Factors. International Journal of Molecular Sciences, 2020;21(8): 2671.

11. TORRES T, et al. Update on Atopic Dermatitis. Acta Médica Portuguesa, 2019; 32(9):606-613.

12. WANG V, et al. The infectious complications of atopic dermatitis. Annals of Allergy, Asthma \& Immunology, 2021; 126(1):3-12.

13. WILLIAMS HC, CHALMERS J. Prevention of Atopic Dermatitis. Acta Dermato-Venereologica, 2020; 100(12): adv00166.

14. WOODS CA. Overview of atopic dermatitis. The American journal of managed care, 2017;23(8 Suppl): S115-S123.

15. YANG G, et al. Skin Barrier Abnormalities and Immune Dysfunction in Atopic Dermatitis. International Journal of Molecular Sciences, 2020;21(8): 2867.

16. YOSIPOVITCH G, et al. Neuroimmune interactions in chronic itch of atopic dermatitis. The Journal of the European Academy of Dermatology and Venereology, 2020;34(2):239-250. 